\title{
Improved Tat-mediated plasmid DNA transfer by fusion to LK15 peptide
}

\author{
Amer F. Saleh ${ }^{1}$, Harmesh Aojula, Yamini Arthanari, Shaun Offerman, Myasar Alkotaji, Alain Pluen * \\ Drug Delivery Group, School of Pharmacy and Pharmaceutical Sciences, University of Manchester, United Kingdom
}

\section{A R T I C L E I N F O}

\section{Article history:}

Received 21 September 2009

Accepted 23 December 2009

Available online $\mathrm{xxxx}$

\section{Keywords:}

Tat

LK15

Membrane active

Cell penetrating peptide

Gene delivery

Spheroids

\begin{abstract}
A B S T R A C T
The use of cell penetrating peptides (CPPs), such as Tat-derived peptide, to deliver DNA into cells is limited as evidenced by the low transfection efficiency of their DNA complexes. Here, we demonstrate that covalent attachment of membrane active peptide LK15 to Tat peptide improves gene transfer. Our results demonstrate that Tat peptide was able to form complexes with DNA, but their transfection efficiency was insufficient as assessed by luciferase assay. The attachment of LK15 to Tat significantly improved the physiochemical properties of the DNA complexes, rendered the complexes membrane active and enhanced the gene expression in HT29 and in HT1080 cultured cells. The enhanced transfection ability of Tat-LK15 compared to Tat is likely to be due mainly to the higher uptake of DNA. Finally, we evaluated the penetration and transfection ability of Tat and Tat-LK15 in multicellular tumour spheroids (MCTS) to mimic in vivo delivery to tumours. The results showed that the penetration and transfection ability of Tat and Tat-LK15/ DNA complexes were limited to the rim of HT29 spheroids. Taken together, our data shows improvement in the transfection efficiency of Tat peptide by covalent attachment to LK15. Further advancements are needed before any potential applications in tissues as the penetration into the core of MCTS remains severely restricted.
\end{abstract}

(c) 2010 Elsevier B.V. All rights reserved.

\section{Introduction}

Several gene delivery tools have been developed to introduce therapeutic genes into target cells. Non-viral vectors, such as polymer- and cationic lipid-based systems, have been developed as an alternative to viral vectors. However, the efficiency of non-viral vectors is low compared to viral vectors; therefore, continuing efforts to design less toxic and more efficient gene delivery vectors have led to considering cell penetrating peptides (CPPs). Among these, Tatderived peptide, one of the most widely characterised CPPs, is an arginine-rich sequence (comprising amino acids 49-57) derived from the transactivating transcriptional activator protein of human immunodeficiency virus type 1 (HIV-1 TAT protein). The unique ability of Tat-derived peptide to translocate across the plasma membrane has been successfully utilised to enhance the intracellular delivery of various bioactive molecules across the plasma membrane, including the delivery of DNA $[1,2]$. However, the exact mechanism involved in the cellular internalisation of CPPs remains controversial. Though being often less toxic than other non-viral vectors, the level of gene transfer mediated by CPPs still lags behind lipid-based formula-

\footnotetext{
* Corresponding author. School of Pharmacy and Pharmaceutical Sciences, University of Manchester, Stopford Building, Oxford Road, Manchester M13 9PT United Kingdom. Tel.: + 441612751792

E-mail address: alain.pluen@manchester.ac.uk (A. Pluen).

Present address: Division of Protein and Nucleic Acid Chemistry, MRC Laboratory of Molecular Biology, Cambridge, United Kingdom.
}

tions [3]. Moreover, the ability of vectors to facilitate gene expression in cell monolayers alone is not sufficient to predict the likely success in tissues. Indeed, as the ultimate goal is to apply gene delivery systems to tissues, only those systems which are able to penetrate and transfect tissues are worthy of consideration for therapeutic applications. Unfortunately, there is a paucity of data on this aspect of delivery. Thus, it is important to evaluate non-viral vectors in cellular models that closely mimic tumours in vivo. For this purpose multicellular tumour spheroids (MCTS) were used as a relevant model for avascular tumours and metastases [4]. Spheroids display several microenvironment conditions found in tumours, as well as cell to cell contact, and cell to matrix interactions which can affect the penetration of molecules [4,5]. In fact and to our knowledge, no studies of the penetration in spheroids involving Tat as a DNA vector have been published.

We have recently reported that covalent attachment of YIGSR pentapeptide, known to target cell-surface laminin receptors, to Tatderived peptide can improve the transfection efficiency in laminin receptor-positive cells (HT1080), but the levels were still low compared to well established vectors such as lipofectin [6]. On the other hand, Perry et al. [7] have assessed a short ideal amphipathic peptide (LK15) combining both membrane activity and DNA condensation ability to serve as a single component gene delivery carrier [8]. Unfortunately, LK15 suffers from relatively poor transfection efficiency and thus may be amenable to further modifications. Consequently, it seemed worthwhile to explore whether a new multifunctional peptide based on Tat and LK15 vectors would 
improve the delivery efficiency of the DNA complexes. Therefore, Tatderived peptide was covalently linked through its C-terminal to the LK15 sequence to construct Tat-LK15 peptide (see Table 1).

In this study, the ability of Tat-LK15 peptide to form complexes with DNA was tested and compared against Tat and LK15 peptides. All peptides (Tat, LK15, and Tat-LK15) were able to complex DNA, but only Tat-LK15 mediated significant DNA uptake into cells. DNA complexes with Tat-LK15 showed no cytotoxicity but increased transfection efficiency compared to Tat although still lower than PEI and lipofectin. Evaluation of DNA uptake and gene expression mediated by Tat and Tat-LK15 in MCTS revealed that the limited penetration into MCTS represents a major barrier for gene delivery. The findings provide new insights into the design of CPPs-based vectors as gene transfer agents.

\section{Materials and methods}

\subsection{Materials}

General cell culture reagents were purchased from GibcoBRL (Paisley, UK). Dulbecco's Modified Eagle Medium (DMEM) was purchased from Sigma (UK). Plasmids pEGFPLuc (6.4 kbp) and pDsRed2-1 (4.1 kbp) were obtained from BD Biosciences (Oxford, UK). The intercalating dye YOPRO-1 was purchased from Invitrogen (UK). Branched polyethyleneimine (PEI, $2 \mathrm{kDa}$ ) was purchased from Sigma (UK). Lipofectin was purchased from Invitrogen (UK). The Luciferase assay kit was purchased from Promega (UK). DRAQ5 ${ }^{\mathrm{TM}}$ was purchased from Biostatus (UK). Fluorescein and Cy5 nucleic acid labelling kits were purchased from Mirus (LabelIT, USA).

\subsection{Peptide synthesis and purification}

The primary amino acid sequences of peptides used in this study are listed in Table 1. Peptide LK15 was synthesized and purified to more than 95\% purity by Advanced Biomedical Limited (Oldham, UK). Tat and Tat-LK15 peptides, were synthesized by solid-phase using the standard t-Boc chemistry. The MBHA resin $(0.62 \mathrm{mmol} / \mathrm{g})$ and Bocprotected amino acids were purchased from Novabiochem (Nottinghamshire, UK). The cleaved peptides were purified by reverse phase HPLC on a semi-preparative C8 Vydac column $(22 \mathrm{~mm} \times 250 \mathrm{~mm})$ using $0.1 \% \mathrm{v} / \mathrm{v}$ trifluoroacetic acid in water and $80 \% \mathrm{v} / \mathrm{v}$ acetonitrile containing $0.1 \%$ TFA linear gradient at flow rate of $7 \mathrm{ml} / \mathrm{min}$ for $45 \mathrm{~min}$. Peptides were purified to more than $95 \%$ purity as assessed by reverse phase HPLC (C8-Vydac column $4.6 \mathrm{~mm} \times 250 \mathrm{~mm}$ ) and the molecular mass of the peptides was confirmed by MALDI-TOF mass spectrometry (micromass, Tof Spec $2 \mathrm{E}$ ). The molecular mass values of molecular ion $[\mathrm{M}+\mathrm{H}]^{+}$were in close agreement $( \pm 0.5$ unit) with the calculated mass of each peptide.

\subsection{Cell culture}

HT29 (human colorectal adenocarcinoma) and HT1080 (human connective tissue fibrosarcoma) cell lines were grown in DMEM supplemented with $10 \%(\mathrm{v} / \mathrm{v})$ FCS (Biowest, UK), penicillin/streptomycin $(10 \mu \mathrm{g} / \mathrm{ml})$ and $2 \mathrm{mM}$ L-glutamine. Cells were maintained at $37^{\circ} \mathrm{C}$ in a humidified $5 \% \mathrm{CO}_{2}$ incubator.

Table 1

Amino acid sequences of peptides.

\begin{tabular}{ll}
\hline Peptide & Sequence \\
\hline Tat & RKKRRQRRRGGG-CONH \\
LK15 & KLLKLLLKLLLKLLK-COOH \\
Tat-LK15 & RKKRRQRRRGGGKLLKLLKLLLKLLK-CONH 2 \\
\hline
\end{tabular}

\subsection{Formation of vector/DNA complexes}

One microgram of plasmid DNA $(0.2 \mathrm{mg} / \mathrm{ml}$ stock $)$ was diluted to a volume of $25 \mu \mathrm{l}$ in HEPES-buffered saline (10 mM HEPES, $150 \mathrm{mM}$ $\mathrm{NaCl}, \mathrm{pH} 7.4)$. Similarly the corresponding amount of the vector to the desired $(+/-)$ charge ratio was diluted in $25 \mu$ l of HEPES-buffered saline. For Tat peptide, a stock solution of $0.5 \mathrm{mg} / \mathrm{ml}$ in HEPESbuffered saline was used. In the case of Tat-LK15 peptide, a peptide stock solution of $0.2 \mathrm{mg} / \mathrm{ml}$ in HEPES-buffered saline was used. For PEI, a $1 \mathrm{mg} / \mathrm{ml}$ stock solution in HEPES-buffered saline was used. The vector solution was added dropwise to the DNA solution and followed by agitation for $20 \mathrm{~s}$. The resulted solution was then allowed to incubate at room temperature for $30 \mathrm{~min}$ before use. DNA complexes with lipofectin were prepared according to the manufacturer's instruction (Invitrogen). DNA solution $(1 \mu \mathrm{g})$ was diluted in OptiMEM-1 reduced serum medium $(100 \mu \mathrm{l})$. The amount of lipofectin to produce the required weight ratio was diluted in Opti-MEM-1, then added to the DNA solution, mixed gently, and incubated for $15 \mathrm{~min}$ at room temperature.

\subsection{Fluorescence assay}

Increasing amounts of peptide were added to a $10 \mu \mathrm{g} / \mathrm{ml}$ plasmid DNA (pEGFPLuc) labelled with YOPRO-1 at (dye: base pair) of 1:50 prepared in $10 \mathrm{mM}$ HEPES buffer $\mathrm{pH} 7.4$ as mentioned above. After $10 \mathrm{~min}$, the fluorescence intensity was measured at $509 \mathrm{~nm}$ (excitation $490 \mathrm{~nm}$ ) according to the procedure described by Saleh et al. [6]. The change in fluorescence upon the addition of peptide is expressed as the percentage of the fluorescence of DNA/dye alone against $(+/-)$ charge ratio.

\subsection{Size and zeta potential measurement}

Solutions of peptide/DNA complexes were prepared as described above at a DNA concentration of $10 \mu \mathrm{g} / \mathrm{ml}$ in $10 \mathrm{mM}$ HEPES-buffered saline. Particle size was determined by dynamic light scattering and zeta potentials were measured by electrophoretic method using the Zetasizer 3000 HS (Malvern Instruments, UK). Results are expressed as the average of three measurements.

\subsection{Liposome leakage assay}

Phosphatidylcholine from Egg Lecithin (Lipoid GmbH, Germany) and cholesterol (Sigma, UK) were dissolved at a 2:1 molar ratio in 1:1 Chloroform:Methanol. The lipid was then reduced to a thin film in a rotary evaporator (water bath at $40{ }^{\circ} \mathrm{C}$ and rotation to $200 \mathrm{rpm}$ ) under vacuum. Once dry, the film was hydrated with $4 \mathrm{ml}$ of solution containing $120 \mathrm{mM}$ Calcein $20 \mathrm{mM} \mathrm{NaCl}$ and $10 \mathrm{mM}$ Phosphate $\mathrm{pH}$ 7.4. Then, the resulting solution was gently swirled to remove the film from the sides of the flask. Unilamellar vesicles were formed by ten extrusions through a $200 \mathrm{~nm}$ polycarbonate membrane at high pressure extruder (Avestin Inc) and at room temperature. Any unencapsulated dye was removed via size exclusion gel filtration through Sepharose 6B column. The concentration of phospholipids was determined by Stewart assay [9]. To form complexes peptides were added into DNase/Rnase free eppendorfs with the appropriate concentration of the plasmid pEGFPLuc to comprise either $3: 1$ or $10: 1$ charge ratio. After 5-minute incubation a $10 \mu$ l aliquots of the complexes corresponding to $0.1 \mathrm{nmol}$ of peptide were placed into wells of a microtitre plate (Iwaki, Japan) containing $180 \mu \mathrm{l}$ of $10 \mathrm{mM}$ Hepes $140 \mathrm{mM} \mathrm{NaCl} \mathrm{pH} 7.4$ to which $10 \mu \mathrm{l}$ of Calcein liposomes $(0.3 \mathrm{mg} / \mathrm{ml}$ lipid) were added. Calcein release was determined by fluorescence emission at $520 \mathrm{~nm}$ (excitation $488 \mathrm{~nm}$ ) using a spectrofluorimeter after a 25-minute incubation. The initial Calcein fluorescence was subtracted from the total fluorescence mediated by 
the peptide and plotted as a percentage of total fluorescence obtained in the presence of $0.1 \%$ Triton X-100 solution [10].

\subsection{FACS analysis}

The plasmid pDsRed2-1 was labelled with Fluorescein and Cy5 nucleic acid labelling kits according to instructions from the manufacturer (Mirus, USA). Cells were seeded into a 6-well culture plate at a density to obtain $70 \%-80 \%$ confluence on the day of the experiment. The culture medium was removed and cells rinsed once with $1 \mathrm{ml}$ PBS and once with Opti-MEM-1 reduced serum medium. The cells were then incubated at $37{ }^{\circ} \mathrm{C}$ in Opti-MEM- $1(1 \mathrm{ml})$ containing $1 \mu \mathrm{g}$ of fluorescein-labelled DNA complexed with the indicated vector as described above. After $4 \mathrm{~h}$, the medium was removed, and the cells were rinsed twice with PBS. To avoid the influence of membrane-bound complexes, $0.5 \mathrm{ml}$ of trypan blue solution $0.4 \% \mathrm{w} / \mathrm{v}$ (Sigma, UK) was added into each well [11], and then washed twice with PBS. The cells were trypsinized using $0.1 \% \mathrm{v} / \mathrm{v}$ trypsin/EDTA in PBS for 5 min at $37^{\circ} \mathrm{C}$. DMEM supplemented with $10 \%(\mathrm{v} / \mathrm{v})$ foetal calf serum (FCS) was then added to each well and the cells were centrifuged at $1000 \mathrm{rpm}$ for $5 \mathrm{~min}$. The supernatant was discarded and the cell pellet was resuspended in ice-cold PBS $(0.5 \mathrm{ml})$. For low temperature experiments, uptake was performed as described above, except cells were pre-incubated for $15 \mathrm{~min}$ at $4{ }^{\circ} \mathrm{C}$ before the addition of the vector/DNA and the remaining step were carried out at $4{ }^{\circ} \mathrm{C}$ with pre-cooled solutions. Fluorescence analysis was performed immediately at a minimum of 10,000 events/sample using fluorescence-activated cell sorter FACS (Becton Dickinson, UK) set up to detect green fluorescence (Ex $490 \mathrm{~nm}, \mathrm{Em} 520 \mathrm{~nm}$ ) or red fluorescence (Ex 633, Em 660). Cell viability was determined based on live cells being gated based on forward and sideward scatter.

\subsection{Transfection}

Cells were seeded into 6-well plates at a density of $3 \cdot 10^{5}$ and $2 \cdot 10^{5}$ cells per well for HT 29 and HT 1080 respectively, and incubated overnight to about $70 \%$ confluence in $2 \mathrm{ml}$ of DMEM containing $10 \%$ (v/v) FCS at $37{ }^{\circ} \mathrm{C}$ in a $5 \% \mathrm{CO}_{2}$ atmosphere. The culture medium was discarded and cells were washed with PBS. Peptide/DNA complexes $(50 \mu \mathrm{l})$ were added to each well up to a final volume of $1 \mathrm{ml}$ in OptiMEM-1 reduced serum medium. After $4 \mathrm{~h}$, the medium was discarded and replaced by $2 \mathrm{ml}$ of DMEM containing 10\% (v/v) FCS. After $24 \mathrm{~h}$, the culture medium was discarded and cells were washed with PBS. Cell culture lysis reagent ( $400 \mu \mathrm{l}$ ) obtained from Promega was added to each well and incubated for $30 \mathrm{~min}$ at room temperature. The luciferase activity was measured using the luciferase assay kit (Promega) and normalized to the total protein content of cell lysate as determined by the BCA protein assay.

For low temperature experiments, transfections were performed as described above, except cells were pre-incubated for 15 min at $4{ }^{\circ} \mathrm{C}$ before the addition of the vector/DNA and the transfection was allowed to continue at $4{ }^{\circ} \mathrm{C}$.

For chloroquine experiments, transfections were performed as described above, except cells were pre-incubated in the presence of $100 \mu \mathrm{M}$ of chloroquine (Sigma) for $15 \mathrm{~min}$ at $37^{\circ} \mathrm{C}$ before the addition of the vector/DNA complexes and during the transfection.

For the inhibition of endocytosis, transfection efficiencies of TatLK15 complexes were modified using the following "specific" inhibitors: chlorpromazine (inhibition of clathrin mediated endocytosis), filipin and nystatin (inhibition of caveolae mediated endocytosis) and cytochalasin D (inhibition of macropinocytosis) all purchased from Sigma (UK). Cells were pre-treated for 30 min with $1 \mathrm{ml}$ Opti-MEM-1 containing one endocytosis inhibitor at a chosen concentration (their cytotoxicity was determined by MTT assay see supplementary Fig. S1). Then Tat-LK15/DNA complexes at the optimal charge ratio ( $1 \mu \mathrm{g}$ DNA) were added in presence of endocytosis inhibitor and transfection was allowed to continue for $4 \mathrm{~h}$. Next, the medium was aspired, cells were rinsed with $1 \mathrm{ml}$ PBS and finally $2 \mathrm{ml}$ fresh culture medium added to each well and the cells were incubated for $24 \mathrm{~h}$. The remaining steps were carried as described above.

\subsection{Vector and vector/DNA complexes cytotoxicity}

Cytotoxicity of the vector/DNA complexes was evaluated using the colorimetric (3-[4,5-Dimethylthiazol-2-yl]-2,5-diphenyltetrazolium bromide (MTT)) assay [12] as described by Saleh et al. [6] excepto3 cells were seeded into 96 -well plate at a density of $5 \times 10^{3}$ cells per well and incubated overnight at $37^{\circ} \mathrm{C}$. Then, the cells were incubated for $4 \mathrm{~h}$ with $200 \mu \mathrm{l}$ of Opti-MEM-1 reduced serum medium containing $1 \mu \mathrm{g}$ of DNA complexed with the different vectors or with different concentrations of Tat and Tat-LK15 peptide so that the final concentrations would range from 0.1 to $100 \mu \mathrm{M}$. Following incubation, cells were washed with PBS and incubated in serum-containing medium for an additional $24 \mathrm{~h}$.

\subsection{Spheroid culture}

Each well of 96-well plates was coated with $50 \mu \mathrm{l}$ of $1.5 \% \mathrm{w} / \mathrm{v}$ agarose dissolved in DMEM and air dried for $30 \mathrm{~min}$ at $37^{\circ} \mathrm{C}$. A singlecell suspension was generated from trypsinized monolayers and diluted in DMEM supplemented with $10 \%$ (v/v) FCS to the desired cell density. A volume of $200 \mu \mathrm{l}$ of cell suspension containing $2 \times 10^{3}$ cells was then dispensed into each well of the agarose-coated plates. The plates were then incubated at $37^{\circ} \mathrm{C}$ in $5 \% \mathrm{CO}_{2}$. After 3 days, a spheroid with a diameter of $250 \pm 12 \mu \mathrm{m}$ was generated in each well as measured by a $10 \times$ reticular eyepiece used with $10 \times$ objective of a stage microscope.

\subsection{Transfections of spheroids}

Transfections of spheroids were carried out as described by Mellor et al. [30]. On the third day following spheroids generation, spheroids were transferred to a new 96-well plate coated with agarose at one spheroid per well. Then, $200 \mu$ of Opti-MEM-1 reduced serum medium containing peptide/DNA complexes was added to each well ( $1 \mu \mathrm{g}$ of pDNA per well). Following a 24-hour incubation period at $37^{\circ} \mathrm{C}$, FCS was added to each well to a final concentration of $10 \%(\mathrm{v} / \mathrm{v})$ followed by an additional incubation for $24 \mathrm{~h}$. Spheroids were then individually transferred to a microcentrifuge tube and mixed with $200 \mu \mathrm{l}$ of reporter lysis reagent for $20 \mathrm{~min}$ at $25^{\circ} \mathrm{C}$. Measurement of luciferase activity was performed as described previously.

\subsection{Confocal microscopy}

After $46 \mathrm{~h}$ transfection, DRAQ5 was added to each well to a final concentration of $10 \mu \mathrm{M}$ and incubated for a further $2 \mathrm{~h}$ at $37^{\circ} \mathrm{C}$. Spheroids were then washed by PBS and transferred into a $\mu$-slide 8 well (Ibidi, Germany) and observed by confocal microscopy (LSM510 Confocor 2, Carl Zeiss, Germany) with a $20 \times 0.5 \mathrm{NA}$ objective. Optical sections ( $650 \mu \mathrm{m} \times 650 \mu \mathrm{m}$, every $4 \mu \mathrm{m}$ ) were taken from the upper surface of the spheroids towards the centre to a maximum depth of $60 \mu \mathrm{m}$. Each section is the average of 4 images. DRAQ5 was excited using a 633-nm He-Ne laser (dichroic beamsplitter 514/633 and LP 650 filter). Enhanced green fluorescent protein (EGFP) was detected using an argon laser with an excitation wavelength of $488 \mathrm{~nm}$ (dichroic beamsplitter 488 and LP 505 filter).

To observe the localisation of peptide/DNA complexes, fluorescein-labelled pDsRed2-1 was complexed with the peptide and visualised by confocal microscope as described above. The green fluorescence of fluorescein-labelled pDNA was induced using an argon laser (488-nm, dichroic beamsplitter 488 and LP 505 filter) and 
the fluorescence of Cy5-labelled DNA was observed using a 633-nm He-Ne laser (dichroic beamsplitter 514/633 and LP 650 filter). Stack of images were deconvolved using the software AutoDeblur (MediaCybernetics, US) in 3D blind deconvolution mode (adaptative point spread function).

\subsection{Statistical analysis}

Statistical differences between the mean values of different groups were evaluated by unpaired student's $t$-test. A $p$-value $\leq 0.05$ was considered significant.

\section{Results}

\subsection{Formation of peptide/DNA complexes}

DNA complexation by cationic peptides is generally based on ionic interactions between the positively charged amino acids and the negatively charged phosphate groups of the DNA $[13,14]$. The ability of peptides (Tat, LK15, and Tat-LK15) to form complexes with the plasmid pEGFPLuc was investigated using the displacement/quenching of YOPRO-1 dye [15] (Fig. 1). At a $(+/-)$ charge ratio of $1: 1$, a sharp decrease $(>80 \%)$ in the relative fluorescence was observed with Tat and Tat-LK15 peptides. At $(+/-)$ charge ratios higher than $1: 1$, minimal level of fluorescence was observed in presence of Tat and Tat-LK15, reaching a plateau at approximately 3:1. Besides that, LK15 peptide has a lower ability to displace/quench YOPRO-1 fluorescence (about $8 \%$ remaining at 10:1 charge ratio) which is usually regarded as a reduced ability to bind to DNA compared to Tat and Tat-LK15 (higher residual fluorescence at all $(+/-)$ charge ratios examined).

To further characterize the peptide/DNA complexes, the size and the charge of the complexes were assessed using dynamic light scattering and zeta potential. As the decrease in fluorescence reached a plateau at a $(+/-)$ charge ratio of approximately 3:1 (see above), the size and the charge of the DNA complexes were determined at this $(+/-)$ charge ratio as well as the charge ratio 10:1 to find out whether additional amounts of peptide resulted in different complexes (Table 2); indeed Tat/DNA complexes were shown to have the highest transfection efficiency at this ratio in a previous study [6]. Interestingly for Tat-LK15 peptide, there is no significant variation of the size or the charge of the Tat-LK15/DNA complexes between 3:1 and 10:1 charge ratio complexes (see Table 2). Tat-LK15/DNA complexes showed a diameter of approximately $400 \mathrm{~nm}$, while 3:1 and 10:1 charge ratios of Tat/DNA complexes had diameters larger than 2 and $1 \mu \mathrm{m}$ respectively. Additionally, only slightly positively charged DNA complexes (zeta potential approximately 4 and $9 \mathrm{mV}$ ) were observed using Tat as a vector, while the zeta potential of TatLK15/DNA complexes reached 20-25 mV (Table 2). Overall, the attachment of LK15 to Tat resulted in smaller DNA complexes with a higher charge density.

Having defined the physicochemical properties of the Tat-LK15 and Tat/DNA complexes, we sought to determine the toxicity of the new Tat-LK15 peptide either as a peptide or complexed to DNA.

Next, the effect of attachment of LK15 to Tat on cytotoxicity was assessed in HT29 cells using MTT colorimetric assay as peptide and as a vector (Fig. 1b and c). Fig. 1b indicates that, as expected, Tat peptide is non toxic up to $100 \mu \mathrm{M}$ in HT29 cells. On the other hand, Tat-LK15 peptide's toxicity increases rapidly with the peptide's concentration. Indeed the cell viability is only $70-80 \%$ and $50 \%$ at 1 and $10 \mu \mathrm{M}$ respectively. Nevertheless, the resulting vector/DNA complex e.g. Tat and Tat-LK15-based DNA complexes, showed low toxicity with cell viability remaining higher than $85 \%$ (Fig. 1c). Similarly, low level of cytotoxicity was observed with DNA complexes prepared with PEI and lipofectin. These results show that attachment of LK15 to Tat represents a safe approach to improve plasmid DNA delivery in HT29 cells. a

$$
\begin{aligned}
& \text { DNA binding competition } \\
& \text { assay }
\end{aligned}
$$
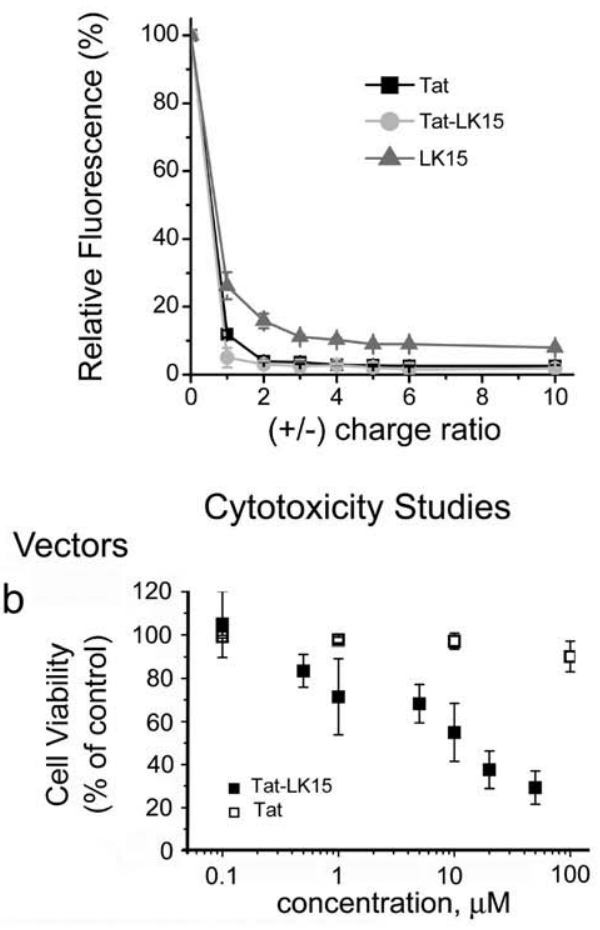

Vector/DNA complexes

C

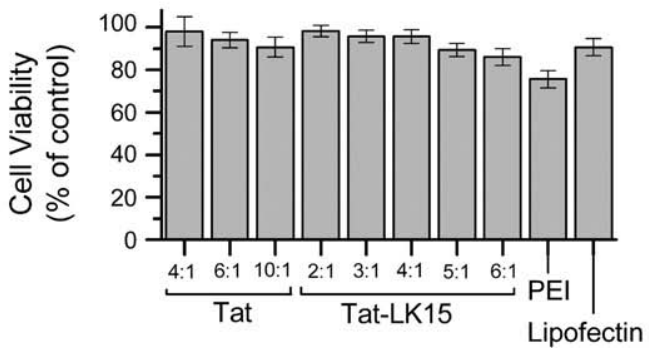

Fig. 1. a. YOPRO-1 fluorescence displacement/quenching assay. Each of LK15, Tat, and Tat-LK15 peptides was added to YOPRO- 1 labelled DNA $(10 \mu \mathrm{g} / \mathrm{ml})$ solution in $10 \mathrm{mM}$ HEPES buffer-saline $(\mathrm{pH} 7.4)$ at various $(+/-)$ charge ratios. The decrease in fluorescence $(\mathrm{Ex}=490 \mathrm{~nm}, \mathrm{Em}=509 \mathrm{~nm})$ is measured and plotted as the percentage of fluorescence of DNA/YOPRO-1 alone. The values represent the mean \pm S.D., $n=3$. b. Cytotoxicity of Tat and Tat-LK15 in HT 29 cells. Cells were incubated for $4 \mathrm{~h}$ at $37^{\circ} \mathrm{C}$ with different amounts of Tat and Tat-LK15 peptides. Cells were washed and incubated in serum-containing medium for another $24 \mathrm{~h}$ before being analysed by MTT assay. Means \pm S.D. of five independent experiments are indicated. c. Cytotoxicity of vector/ DNA complexes in HT 29 cells. Cells were incubated for $4 \mathrm{~h}$ at $37{ }^{\circ} \mathrm{C}$ with $1 \mu \mathrm{g}$ of DNA complexed with Tat and Tat-LK15 at the indicated $(+/-)$ charge ratios. PEI/DNA complexes were prepared at $(+/-)$ of $10: 1$. A $(\mathrm{w} / \mathrm{w})$ ratio of $5: 1$ was used for lipofectin DNA complexes. Cells were washed and incubated in serum-containing medium for another $24 \mathrm{~h}$ before being analysed by MTT assay. Means \pm S.D. of three independent experiments are indicated.

Table 2

Average diameter $(\mathrm{nm})$ and zeta potential $(\mathrm{mV})$ of DNA complexes prepared in $10 \mathrm{mM}$ HEPES buffer-saline ( $\mathrm{pH} 7.4$ ) using a DNA concentration of $10 \mu \mathrm{g} / \mathrm{ml}$. The values represent the mean \pm S.D., $n=3$.

\begin{tabular}{lccc}
\hline Vector & Charge ratio $(+/-)$ & Size $(\mathrm{nm})$ & Zeta potential $(\mathrm{mV})$ \\
\hline Tat-LK15 & $3: 1$ & $400 \pm 186$ & $25.3 \pm 3.4$ \\
Tat-LK15 & $10: 1$ & $536 \pm 23$ & $21.2 \pm 0.6$ \\
Tat & $3: 1$ & $2533 \pm 1543$ & $3.8 \pm 2.4$ \\
Tat & $10: 1$ & $1017 \pm 526$ & $8.9 \pm 1.6$ \\
\hline
\end{tabular}


a

HT1080

HT29

LK15
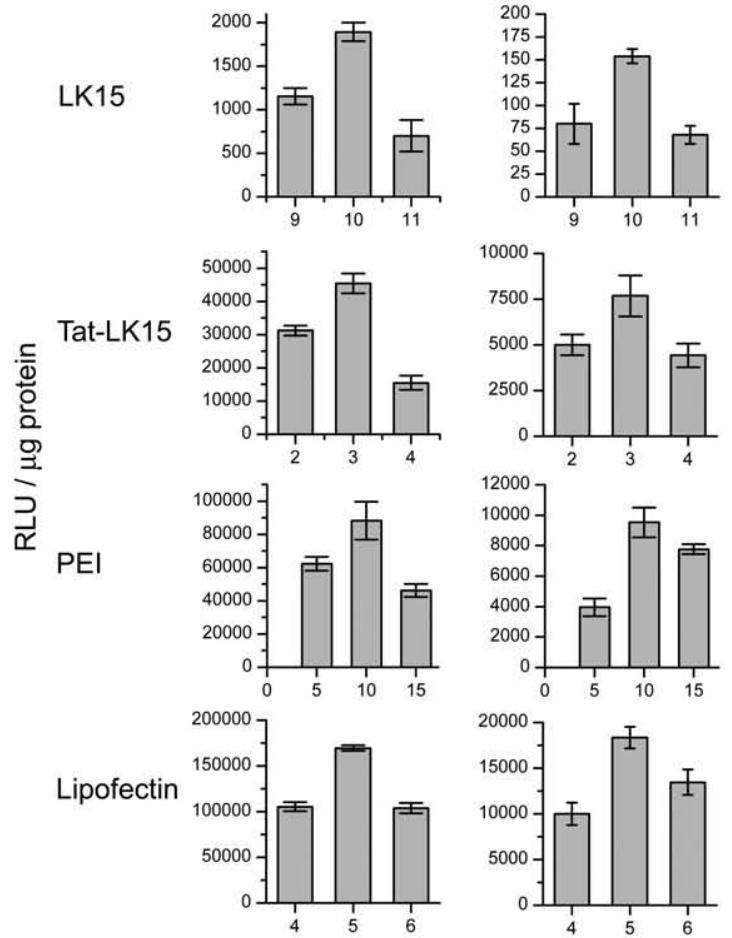

$(+/-)$ charge ratios

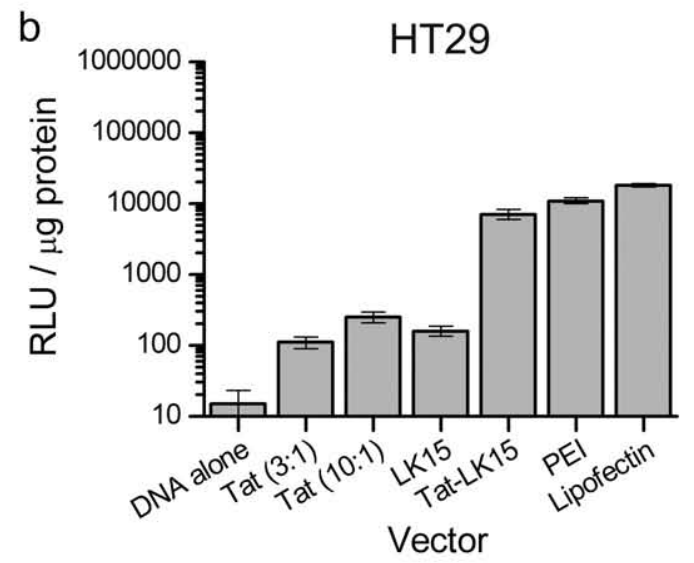

C

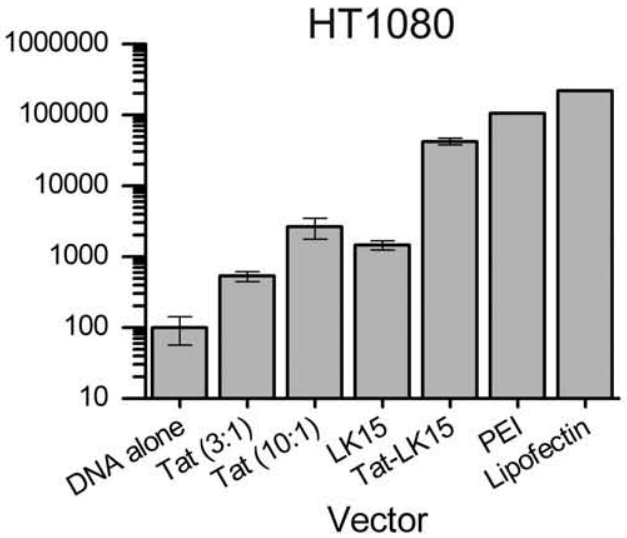

3.2. Transfection efficiencies and cytotoxicity of peptide/DNA complexes

We next assessed the transfection efficiency of Tat and Tat-LK15 peptide vectors in human colorectal adenocarcinoma cells (HT29) and in human fibrosarcoma cell line (HT1080). Transfection with lipofectin and PEI ( $2 \mathrm{kDa}$ ) were used as positive controls $[14,16]$. The $2 \mathrm{kDa}$ PEI was chosen as it mediates efficient gene transfection with reduced cytotoxicity compared to higher molecular weight PEIs [17], and its molecular weight is relatively close to the peptide Tat-LK15. Fig. 2a indicates that for both cell lines the same ratio for vector/DNA complexes results in the highest luciferase expression. Based on Fig. 2a and previously published studies, the optimal charge ratio are 3:1 for Tat-LK15/DNA, (w/w) 5:1 for lipofectin/DNA, $(+/-)$ 10:1 for LK15/DNA and PEI/DNA. Additionally, for Tat peptide, a (+/-) charge ratio of (10:1) was used as supported by our previous study [6] while a 3:1 charge ratio for Tat/DNA was introduced based on the ratio used for the efficient DNA condensation and physicochemical characterisation of the complexes (see Fig. 1 and Table 2).

Overall, Fig. $2 \mathrm{~b}$ and $\mathrm{c}$ show that lipofectin mediated the highest transfection efficiency followed by PEI and Tat-LK15, while LK15- and Tat-based complexes were the least efficient in HT 29 and HT1080 respectively. Interestingly, Tat-LK15 peptide mediated transfection was between one and two order of magnitude higher than that of Tat or LK15. These results indicate that the attachment of the amphipathic peptide LK15 to Tat was markedly beneficial with respect to the transfection efficiency.

\subsection{Effect of low temperature $\left(4^{\circ} \mathrm{C}\right)$ on the transfection efficiency}

To examine whether Tat and Tat-LK15 facilitate gene transfer via an energy-dependent process, transfections were carried out at low temperature $\left(4^{\circ} \mathrm{C}\right)$ and compared to transfections at $37^{\circ} \mathrm{C}$ (Fig. 3a). Incubation at $4{ }^{\circ} \mathrm{C}$ significantly reduced gene expression mediated by all four vector-based complexes. The gene expression was reduced by about $90 \%$ for Tat-LK15 and PEI vectors, and about 70\% and 50\% for Tat and lipofectin vectors respectively. These results clearly suggest that an ATP driven-mechanism (e.g. endocytosis) is mainly involved in the uptake for these vectors. Nevertheless, any detectable gene expression observed at $4{ }^{\circ} \mathrm{C}$ with Tat-LK15, PEI and lipofectin-based complexes may be partially imputed to transfection artefacts including non-specific attachment and other ATP-free mechanisms. The presence of a second mechanism is more likely for lipofectinbased complexes (50\% initial level) and may suggest the involvement of a membrane fusion mechanism.

\subsection{Cellular uptake of peptide/DNA complexes at $37^{\circ} \mathrm{C}$ and $4{ }^{\circ} \mathrm{C}$}

To better understand the reason behind the enhanced transfection efficiency of Tat-LK15 compared to Tat, we assessed the uptake of DNA complexes in HT29 cells by flow cytometry using fluoresceinlabelled plasmid DNA complexed with each vector at the optimal ratio

Fig. 2. a. Determination of the optimal vector/DNA charge ratio in HT29 and HT1080 cells. Optimizing charge or weight ratio for optimal gene transfer in HT29 and HT1080 cells using various vectors complexed with $1 \mu \mathrm{g}$ of pEGFPLuc. The results are expressed as relative light units (RLUs) normalized to total protein content. The values represent the mean \pm S.D., $n=3$. b. Transfection efficiencies of various vectors in HT29 cells. Cells were transfected for $4 \mathrm{~h}$ at $37^{\circ} \mathrm{C}$ with $1 \mu \mathrm{g}$ of pEGFPLuc complexed with the indicated vector at the optimum weight or charge ratio. The luciferase activity was determined $24 \mathrm{~h}$ following transfection. The results are expressed as RLUs normalized to total protein content. The values represent the mean \pm S.D., $n=3$. c. Transfection efficiencies of various vectors in HT1080 cells. Cells were transfected for $4 \mathrm{~h}$ at $37^{\circ} \mathrm{C}$ with $1 \mu \mathrm{gg}$ of pEGFPLuc complexed with the indicated vector at the optimum weight or charge ratio. The luciferase activity was determined $24 \mathrm{~h}$ following transfection. The results are expressed as RLUs normalized to total protein content. The values represent the mean \pm S.D., $n=3$. 


\section{a. Transfection efficiency}
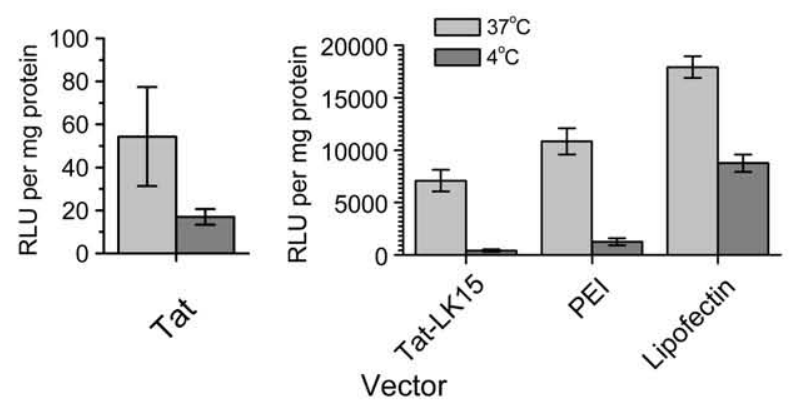

b. Cellular uptake at $37^{\circ} \mathrm{C}$

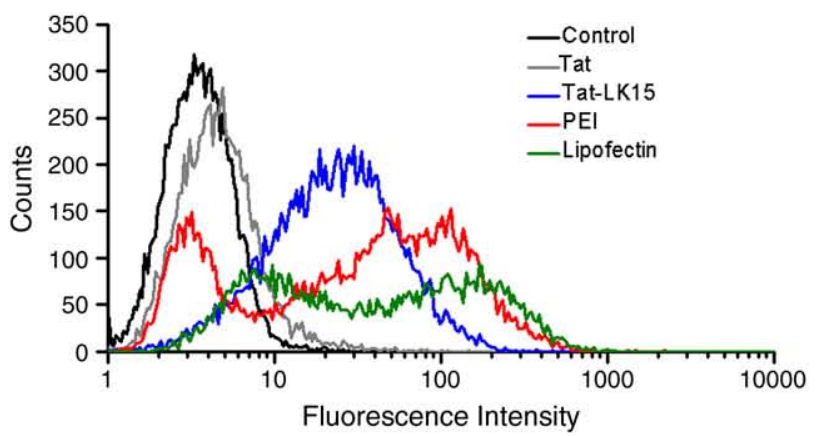

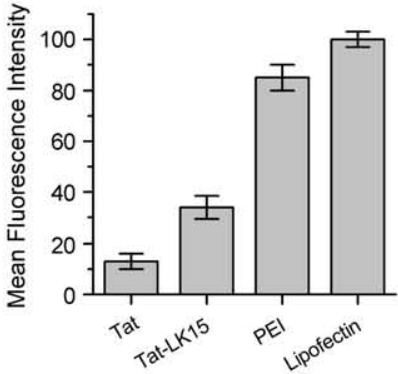

Vector

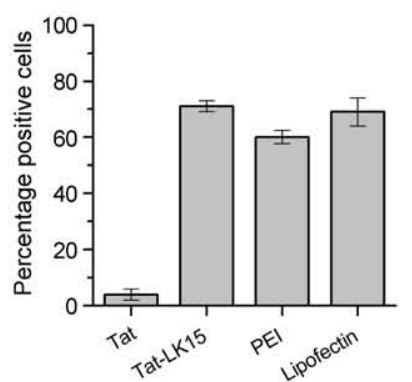

Vector

\section{c. Cellular uptake at $4^{\circ} \mathrm{C}$}


at $37{ }^{\circ} \mathrm{C}$ and $4{ }^{\circ} \mathrm{C}$. Since cell fixation can affect the cellular uptake of cell penetrating peptides, including Tat-derived peptide, FACS analysis was performed using live (unfixed) cells [18]. Fig. 3b and c presents the distribution profiles of DNA uptake mediated by the different vectors. At $37^{\circ} \mathrm{C}$ (Fig. 3b), the profiles of peptide-based vectors appeared more homogenous than those observed with PEI or lipofectin for which a two peak-distribution was observed while at $4{ }^{\circ} \mathrm{C}$, a shift towards lower fluorescence intensities is observed and all vector-based complexes profiles are relatively homogenous and bell shaped. Additionally, at $37^{\circ} \mathrm{C}$ (Fig. 3b) indicates a significant increase in the percentage of positive cells using Tat-LK15/DNA complexes ( $\sim 70 \%)$ compared to Tat-based complexes $(<10 \%)$, approaching similar levels to that of PEI and lipofectin. With regards to the mean fluorescence intensity of cells, Tat-LK15-based complexes resulted in about 2-fold higher fluorescence than Tat-based complexes, yet about 2-2.5 fold less fluorescence than PEI or lipofectin-based complexes $(p$-value $<0.05)$. Finally at $4{ }^{\circ} \mathrm{C}$ (Fig. $3 \mathrm{c}$ ), the mean fluorescence intensity of cells is not affected for Tat- and Tat-LK15-based complexes, while it is significantly reduced for PEI- and lipofectinbased complexes. On the other hand the percentage of positive cells decreases significantly for all vectors at $4{ }^{\circ} \mathrm{C}$ (about $60 \%$ for Tat-LK15based complexes) and to a limited extent for PEI-based complexes.

\subsection{Effect of specific inhibitors on TatLK15 mediated transfection efficiency}

The cytotoxicity of the "specific" inhibitors was determined with a colorimetric MTT assay leading to the choice of their concentrations: $2 \mu \mathrm{g} / \mathrm{ml}$ solution chlorpromazine, $30 \mu \mathrm{g} / \mathrm{ml}$ solution of nystatin, $2 \mu \mathrm{g} / \mathrm{ml}$ solution of filipin and $1 \mu \mathrm{g} / \mathrm{ml}$ solution of cytochalasin were used to inhibit clathrin mediated endocytosis, caveolae mediated endocytosis and macropinocytosis respectively [19-21]. Fig. 4 shows the effect of these specific inhibitors on the Tat-LK15 mediated transfection efficiency.

Fig. 4 indicates a poor influence of these inhibitors on the transfection efficiency of Tat-LK15-based complexes exception made of fillipin and nystatin for which a reduction of about $30 \%$ is observed. Overall this would suggest the partial involvement of caveolae mediated endocytosis for Tat-LK15-based complexes uptake and trafficking but that other endocytotic mechanisms may be involved such as fluid phase endocytosis [22].

\subsection{Effect of chloroquine on the transfection efficiency}

As the effect of "specific" inhibitors was limited on transfection efficiency, we completed this by evaluating whether complexes would end in lysosomes compartments. Therefore, the weak base chloroquine (lysosomotropic agent), the traditional test to evaluate whether complexes were trapped in the endosomes, was used to

Fig. 3. a. Effect of temperature on the transfection efficiency. HT29 cells were transfected for $4 \mathrm{~h}$ at $4{ }^{\circ} \mathrm{C}$ (dark grey) or $37^{\circ} \mathrm{C}$ (light grey) with DNA complexes containing $1 \mu \mathrm{g}$ of pEGFPLuc complexed with the vector at the optimum weight or charge ratio. The luciferase activity was measured $24 \mathrm{~h}$ following transfection. The results are expressed in relative light units (RLUs) normalized to total protein content in the cell lysate. The values represent the mean \pm S.D., $n=3$. b. Cellular uptake of fluorescein-labelled DNA in HT29 cells at $37^{\circ} \mathrm{C}$. Cells were incubated for $4 \mathrm{~h}$ with labelled DNA complexed with the indicated vectors at the optimum charge or weight ratio. The cells were then washed and analysed by flow cytometry. Representative histograms of DNA uptake by different vectors. Mean fluorescence intensity (left) and percentage of positive cells (right) at $37^{\circ} \mathrm{C}$. The values represent the mean \pm S.D., $n=3$. c. Cellular uptake of fluoresceinlabelled DNA in HT29 cells at $4{ }^{\circ} \mathrm{C}$. Cells were pre-incubated for 15 min before a 4 $\mathrm{h}$ incubation with labelled DNA complexed with the indicated vectors at the optimum charge or weight ratio. The cells were then washed and analysed by flow cytometry. Representative histograms of DNA uptake by different vectors. Mean fluorescence intensity (left) and percentage of positive cells (right) at $4{ }^{\circ} \mathrm{C}$. The values represent the mean \pm S.D., $n=3$. FACS profiles symbols: control (-), Tat (-), Tat-LK15 (-), PEI (-) and lipofectin (-). (For interpretation of the references to colour in this figure legend, the reader is referred to the web version of this article.) 
evaluate the endosomal escape ability of Tat-LK15/DNA complexes. Fig. 5 shows the transfection efficiency of Tat, Tat-LK15, PEI, and lipofectin-based complexes in the presence/absence of $100 \mu \mathrm{M}$ chloroquine in HT29 cells. A significant increase $(\sim 50 \%)$ in the level of gene expression was observed in presence of $100 \mu \mathrm{M}$ chloroquine for Tat-LK15-based complexes ( $p$-value $<0.05$ ). In contrast, treatment with chloroquine did not affect the gene expression of Tat-based complexes but reduced the gene expression mediated by PEI and lipofectin, resulting in about $27 \%$ and $34 \%$ reduction in luciferase activity respectively ( $p$-value $<0.05$ ). Such reduction has already been observed for PEI mediated gene transfer in HepG2 and HEK293 cells [23].

\subsection{Membrane activity of peptides}

As our results show a higher cellular uptake and enhanced transfection efficiency for Tat-LK15 compared to Tat (Fig. 3b), we sought to find out whether the composite sequence of Tat-LK15 would still retain some of the membrane activity of LK15 peptide thus possibly contributing to the transfection enhancement. Consequently, the capability of Tat-LK15 peptide to destabilise membranes was compared against the membrane active peptide LK15 as a positive control and against Tat peptide as a negative control (Tat is not known to be membrane active) using a liposome leakage assay [24]. Fig. 6 shows that calcein release from liposomes induced by Tat-LK15 peptide is only marginally lower than LK15 while as expected Tat peptide mediated calcein release is less than $1 \%$. On complexation with DNA, the lytic activity of the Tat-LK15 peptide is reduced as the $(+/-)$ charge ratio decreases. In contrast, the lytic activity of LK15 peptide shows insignificant response to DNA complexation while for Tat peptide the lytic activity remains unchanged and insignificant. The Tat and Tat-LK15 peptide sequences are of different lengths and may indeed have secondary structures or their levels. Such differences can easily affect the nature of lytic mechanism. In addition the aggregation states of the peptide may differ thus altering the size of the lytic pores formed. Thus, it would be reasonable to assume that a strict relationship between lytic activity and uptake is hard to contemplate. It is noteworthy that at the optimum charge ratio of 3:1 that was used in transfection studies considerable residual lytic activity $(\sim 80 \%)$ remains thus providing evidence that the DNA complexes are likely to be membrane active.

\subsection{Gene delivery in multicellular spheroids}

The ability of peptide-based vectors to mediate transfection in cultured cells is important but not sufficient. Thus, we tested the

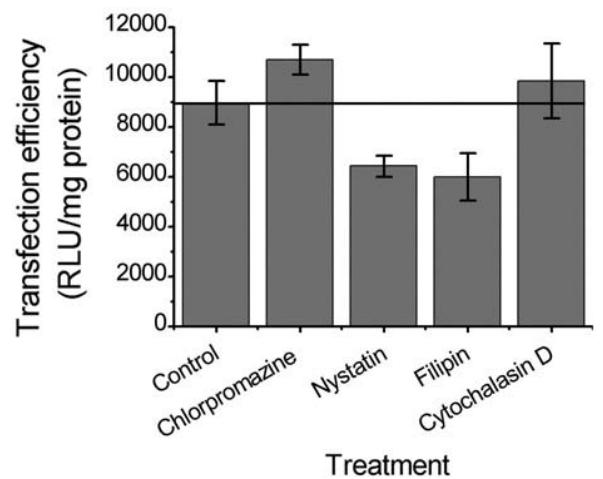

Fig. 4. Effect of endocytosis inhibitors on the transfection activity of peptide mediated gene delivery. HT29 cells were incubated with chloropromazine $(2 \mu \mathrm{g} / \mathrm{ml})$, nystatin $(30 \mu \mathrm{g} / \mathrm{ml})$, filipin $(2 \mu \mathrm{g} / \mathrm{ml})$ and cytochalasin B $(1 \mu \mathrm{g} / \mathrm{ml})$ for $4 \mathrm{~h}$ in the presence of peptide/DNA complexes. The results are expressed in relative light units (RLUs) normalized to total protein content in the cell lysate. The values represent the mean $\pm \mathrm{S}$. D., $n=3$.
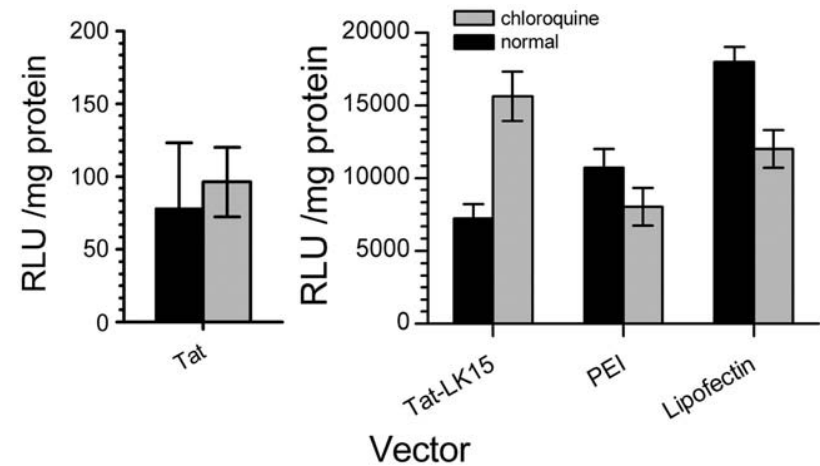

Fig. 5. Effect of chloroquine on the transfection efficiency. HT29 cells were transfected with for $4 \mathrm{~h} 1 \mu \mathrm{g}$ of pEGFPLuc complexed with the vector at the optimum weight or charge ratio in the absence or presence of $100 \mu \mathrm{M}$ chloroquine. The luciferase activity was determined $24 \mathrm{~h}$ following transfection. The results are expressed in relative light units (RLUs) normalized to total protein content in the cell lysate. The values represent the mean \pm S.D., $n=3$.

ability of Tat and Tat-LK15 to penetrate and transfect multicellular tumour spheroids (MCTS) as a robust cancer model - HT29 cells are known to form spheroids [25]. It is noteworthy that for these studies the transfection protocol was modified according to Mellor et al. [30] who incubated the spheroids for $48 \mathrm{~h}$ to maximize expression and to minimise disturbance to the spheroids. Fig. 7 shows the transfection efficiency mediated by Tat and Tat-LK15 peptide (at $+/-$ ) charge ratios of $10: 1$ and 3:1 (respectively) in HT29 spheroids $48 \mathrm{~h}$ post transfection using the luciferase reporter gene (pEGFPLuc). Consistent with the transfection studies using monolayer cells (see insert Fig. 7), the transfection efficiency of Tat-LK15/DNA complexes was about one order of magnitude higher than Tat/DNA complexes ( $p$-value $<0.05$ ).

As the luciferase levels in MCTS are lower than those observed in monolayer cells, the localisation of enhanced green fluorescent protein (EGFP) encoded by pEGFPLuc plasmid was evaluated using confocal microscopy. Fig. 8 shows images taken from the interface glass/spheroid $(0 \mu \mathrm{m})$ then radially inside the spheroid at 20,40 , $60 \mu \mathrm{m}$ depth. EGFP expression appeared to be confined to the rim of the spheroids, but a higher level of EGFP expression was observed using Tat-LK15 compared to Tat peptide. Sections at 40, $60 \mu \mathrm{m}$ depth only indicated EGFP fluorescence in the rim of the spheroids as light attenuation limits deep imaging in MCTS.

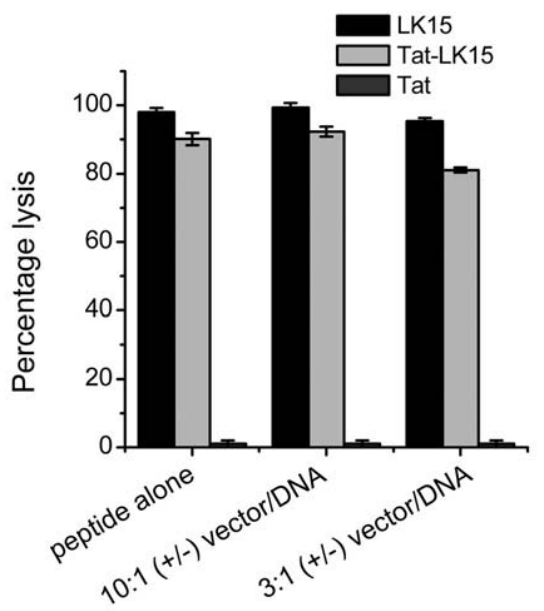

Fig. 6. Evaluation of Peptide and peptide/DNA complex induced liposome leakage. LK15 and Tat-LK15 at a final concentration of $500 \mathrm{nM}$ were incubated for $25 \mathrm{~min}$ in $10 \mathrm{mM}$ HEPES $140 \mathrm{mM} \mathrm{NaCl}$ buffer ( $\mathrm{pH} 7.4)$ containing $10 \mu \mathrm{l}$ of $(0.3 \mathrm{mg} / \mathrm{ml}$ lipid) of calcein liposomes. The increase in fluorescence due to calcein leakage was measured at $540 \mathrm{~nm}$ and plotted as percentage of total fluorescence caused by Triton X-100. The value represent the mean \pm S.D., $n=4$. 
Failure to observe gene expression deep in spheroids may be ascribed to the failure of peptide/DNA complexes to penetrate into the deeper tissue of MCTS. Thus, determining the penetration of peptide/ DNA complexes into spheroids is important to find out whether gene expression correlates to complexes penetration in tissue. Therefore, fluorescein-labelled plasmid (pDsRed2-1) complexed with Tat and Tat-LK15 peptides was used and its distribution in spheroids was evaluated by confocal microscopy after $48 \mathrm{~h}$. Consistent with EGFP expression, high levels of fluorescence were observed at the spheroids' rim, especially at the first sections up $20 \mu \mathrm{m}$ then rapidly decreased (Fig. 8). Additionally, a greater percentage of cells at the surface of the spheroids appear to be associated with the fluorescently-labelled plasmid when incubated with Tat-LK15 peptide than with Tat peptide.

\section{Discussion}

LK15 is an amphipathic peptide which has been reported to form complexes with DNA although its gene delivery efficiency is poor $[7,26]$. On the other hand, cell penetrating peptides (CPPs), such as Tat-derived peptide, have been reported to mediate plasmid DNA delivery into cells $[1,6,27]$; however improving the transfection efficiency of their DNA complexes remains a major challenge. In this study, we evaluated whether covalent attachment of membrane active peptide (LK15) to Tat-derived peptide would enhance the transfection efficiency.

Our results indicate that both Tat and Tat-LK15 peptides were able to significantly displace/quench the YOPRO-1 dye from DNA resulting in reduced level of fluorescence. This suggested efficient DNA binding at $(+/-)$ charge ratio of $1: 1$ and above (Fig. 1$)$. The formation of DNA complexes was also confirmed by light scattering and zeta potential measurements (Table 2). Indeed, Tat peptide formed large size complexes with DNA (micrometer range) with relatively low zeta potentials at $(+/-)$ charge ratio of $3: 1$ and $10: 1$ possibly involving aggregation. On the other hand the addition of an amphipathic peptide LK15 to Tat seems to favour the formation of smaller complexes (approx. 400-500 nm) with an increase of the zeta potential to about $+20-25 \mathrm{mV}$ at the same $(+/-)$ charge ratios.

We also showed that covalent attachment of Tat to LK15 had a favourable effect on the transfection activity compared to Tat and LK15 peptides which substantially exhibited lower transfection activity (Fig. 2) in both HT 29 and HT1080 cells (Fig. 2). Among the different possibilities, the enhanced transfection activity of Tat-LK15-based complexes may be explained in part by their improved physicochemical properties (size and zeta potential) compared to Tat/DNA complexes (Table 2$)$. Indeed, at a $(+/-)$ charge ratio of $3: 1$, the poor

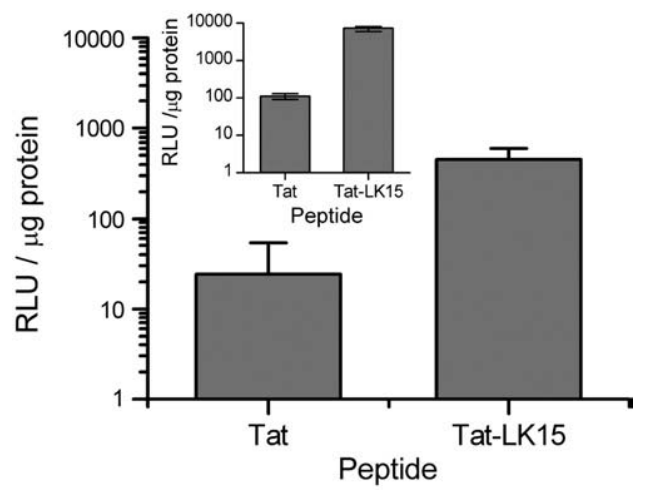

Fig. 7. Transfection efficiency of Tat and Tat-LK15/DNA complexes in HT29 spheroids. HT29 spheroids were incubated for $48 \mathrm{~h}$ at $37^{\circ} \mathrm{C}$ with $1 \mu \mathrm{g}$ of DNA complexed with Tat or Tat-LK15 at $(+/-)$ charge ratio of 10:1 and 3:1 respectively. The luciferase activity was then measured using the luciferase assay. The inset shows gene expression in HT29 grown as monolayers using the standard monolayer transfection protocol. The values represent the mean \pm S.D., $n=3$.

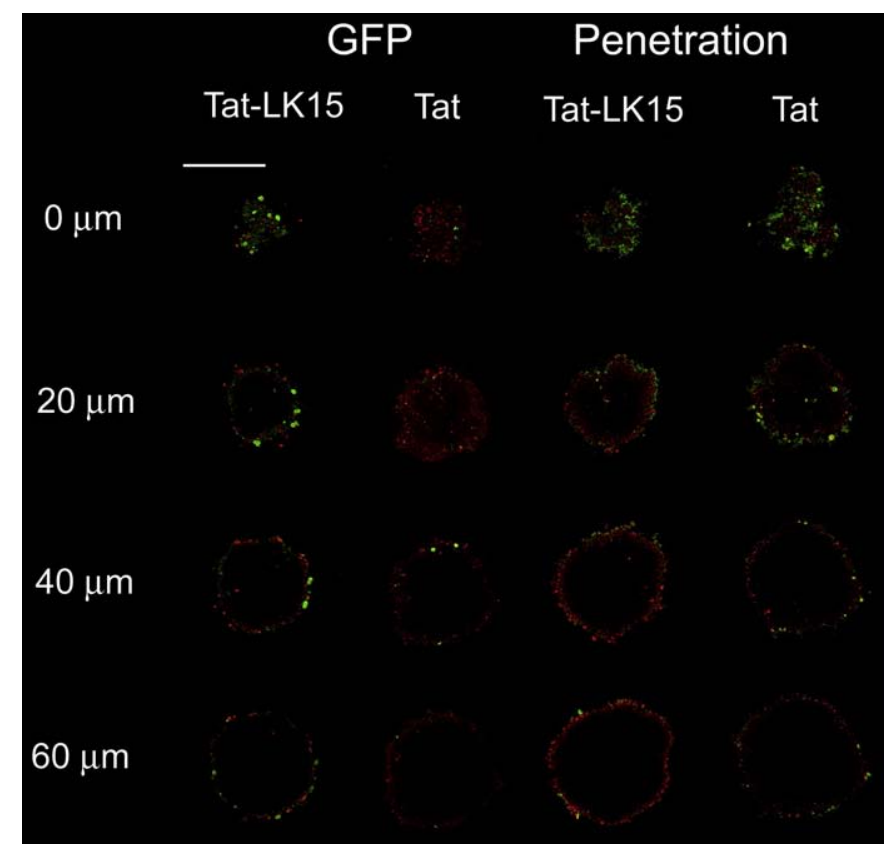

Fig. 8. Localisation of EGFP expression (left) and extent of complexes penetration (right) in HT29 spheroids. HT29 spheroids were transfected for $48 \mathrm{~h}$ at $37^{\circ} \mathrm{C}$ with Tat and Tat-LK15 complexed with $1 \mu \mathrm{g}$ pEGFPLuc plasmid encoding the EGFP (green) at a $(+/-)$ charge ratio of 10:1 and 3:1 respectively. Fluorescein-labelled plasmid DNA was used for penetration studies. DRAQ5 nuclear stain (red) was added at a concentration of $10 \mu \mathrm{M}$ for $2 \mathrm{~h}$ before analysis by confocal microscopy. Images were taken every $20 \mu \mathrm{m}$ up to $60 \mu \mathrm{m}$. Scale bar represents $100 \mu \mathrm{m}$. (For interpretation of the references to colour in this figure legend, the reader is referred to the web version of this article.)

transfection activity mediated by Tat/DNA complexes is consistent with their low zeta potential as well as their large size which is in the upper range of endocytotic uptake (i.e. macropinocytosis). On the other hand, the higher zeta potentials and smaller size of Tat-LK15based complexes may favour their uptake into cells. This was supported by flow cytometry data in which attachment of LK15 to Tat peptide significantly enhanced the cellular binding and uptake of DNA complexes (\% of positive cells and level of uptake) in HT29 cells at $37^{\circ} \mathrm{C}$ and $4{ }^{\circ} \mathrm{C}$. When comparing results to positive controls, PEI and lipofectin, a lower level of DNA uptake was noticeable with Tat-LK15. However this lowered uptake did not have any significant impact on the percentage of positive cells which remained comparable to PEI or lipofectin. This confirms that while cellular uptake of DNA is important other mechanisms or barriers need to be accounted for to improve gene expression. Tat-LK15 peptide remained lytic even after complexation to DNA retaining a high proportion ( $~ 80 \%$, Fig. 6$)$ of its lytic activity. Therefore the improved transfection activity mediated by TatLK15 peptide could also be partially ascribed to its ability to bind to and then destabilise membranes. It was also interesting to note that TatLK15 peptides lytic activity was more responsive to DNA binding than LK15.

Considering membrane activity as a reasonable explanation, it was interesting to know whether it may affect cell uptake or evasion from endosomal vesicles. Our results indicate that treatment of cells with chloroquine strongly improves the transfection efficiency suggesting that, the residual lytic activity of Tat-LK15-based complexes may not be sufficient to aid endosomal escape to high level. A recent study [28] however suggests that chloroquine does not enhance expression solely by promoting endosomal release but other factors are also involved such as the agents ability to protect DNA from degradation and enhance transcription of DNA bound to the vectors. As these additional factors may not be related to lytic activity the actual influence or level of contribution that membrane active LK15 moiety can make to endosomal escape may in fact be underestimated and 
hard to ascertain chloroquine experiment. Interestingly, the addition of chloroquine did not improve the transfection mediated by Tat vector, possibly due to the low level of DNA uptake (Fig. 5). Thus, it is possible that Tat and Tat-LK15-based complexes are internalised into HT29 cells using different trafficking mechanisms. As Tat-LK15 peptide significantly enhanced the cellular uptake of DNA (\% of positive cells and level of uptake) in HT29 cells, it may be plausible that the peptide/DNA complexes being membrane active are better internalised to cause higher uptake, thus improving the transfection efficiency. This aspect may be partially paralleled with the experiments carried out at low temperature $\left(4^{\circ} \mathrm{C}\right.$, Fig. 3 ) and possibly the specific inhibitor studies (Fig. 5). Indeed, transfection efficiencies and binding/uptake were still noticeable at low temperature. While the possibility a non endocytotic mechanism needs further research in order to eliminate experimental artefacts, it is worth keeping in mind that "specific" inhibitors had none or little effect (about 30\% for nystatin and filipin) on transfection efficiency. These results were further supported by flow cytometry (Fig. 3c) as, while significantly reduced compared to $37^{\circ} \mathrm{C}$, a high amount of Tat-LK15/Cy5-DNA complexes were at least bound to the cells at $4{ }^{\circ} \mathrm{C}$ and were not removed by extensive washing. The term "bound" was used as we are not able to separate the fluorescence of bound and taken up Cy5labelled complexes in HT29. Thus our understanding of the complete mechanism of uptake remains unclear: a relatively toxic and haemolytic peptide when complexed is able to carry DNA in cells. Flow cytometry suggests at least attachment to membrane is important but endocytosis inhibitors effect is limited (and to a non acidic route). Further investigation in other endocytotic routes e.g. fluid phase [22] may be worthwhile.

Although being valuable models, cells grown as monolayer cultures lack several three-dimensional features found within the microenvironment of tissues in vivo, including cell to cell and cell-extracellular matrix interactions [29]. Indeed, the ability of the gene delivery vector to penetrate deep into avascular regions located within the core of solid tumours represents an important aspect that needs to be considered during the development of potential gene delivery systems. Thus, to better account for the tumour microenvironment, the delivery of peptides/DNA complexes was studied in MCTS. While the transfection efficiency of Tat-LK15/DNA complexes was about 18fold higher compared to Tat/DNA complexes (Fig. 7), the level of luciferase expression in spheroids was remarkably lower than what measured in monolayer cell culture. Further optimisation of the transfection conditions in MCTS to achieve optimal gene transfer is likely to influence the transfection efficiency as recently suggested by Mellor et al. [30]. However, it is anticipated that even under optimal conditions, the level of gene transfer mediated by Tat and Tat-LK15 peptides would remain lower compared to monolayer cell cultures, possibly due to restricted penetration of the transfection complexes into deeper regions of the spheroids as demonstrated by confocal microscopy (Fig. 8). While proliferating cells may be needed for transfection, their presence cannot fully explain the penetration levels of the peptide/DNA complexes observed in spheroids (Fig. 8). Integrating the fluorescence attenuation in tissues as done by others $[7,31,32]$ did not improve the profile of fluorescence. This is likely due to the strong fluorescence peak in the first couple of cell layers and the very low background fluorescence in deeper sections of the spheroids. Consequently, the transfection/penetration results may simply reflect the absence of diffusion/penetration of the DNA complexes into the spheroid, displaying uptake only by cells located at the spheroid's rim (1-2 layers of cells). Additionally, as Tat and Tat-LK15/DNA complexes are large and positive complexes, it is likely that they cannot diffuse in the extracellular space and are bound negatively charged components of the cell surface or of the extracellular matrix [5,33]. Overall, these initial results suggest that limited penetration of the peptides/DNA complexes into deeper regions within spheroids represents a major barrier for gene transfer in spheroids and cannot be ignored.
Although the endosomal escape mediated by Tat-LK15 peptide is not yet ideal, further improvements are possible. For example, a better rational design to improve the $\mathrm{pH}$-sensitivity of the composite peptide might be required so it can selectively induce endosomal escape in the acidic environment of endosomes. Lundberg et al. [34] have rationally modified penetratin to adopt a secondary structure upon protonation by replacing certain amino acids in the penetratin sequence by histidine. This significantly increased the biological activity of the attached cargo. It may also possible to enhance the pH-sensitivity of Tat-LK15 peptide by replacing the lysine amino acids of LK15 with histidines. Histidine ( $\mathrm{pK}_{\mathrm{a}}$ of $\sim 6.0$ ) can be protonated in the low $\mathrm{pH}$ of endosomes, resulting in buffering effect with subsequent osmotic swelling and endosomal disruption [35]. Recently, a dramatic improvement in the transfection efficiency of Tat peptide was noted upon incorporation of histidine residues [36].

\section{Conclusion}

We have shown that adding a short amphipathic peptide, LK15, could improve the transfection efficiency and DNA uptake mediated by Tat peptide approaching similar levels to those obtained with standard vectors such as PEI and lipofectin. Flow cytometry further supported that attachment of LK15 to Tat significantly enhances the cellular uptake of DNA. So far, the role of LK15 in forming complexes with DNA and its cellular uptake remains unclear. It may participate contribute to the formation of compact complexes while leaving more Tat peptide available on the surface of DNA complexes and potentially increasing their binding with the cell membrane. In fact, further insight into the intracellular trafficking of Tat-LK15 vector is needed. Furthermore, the poor penetration of peptide-based complexes in spheroids suggests that transfection optimisation is needed but also certainly a reduction in size of the DNA complexes. Nevertheless, the enhancement observed both in DNA uptake and transfection levels suggest that this approach in covalently attaching a CPP sequence to an amphipathic sequence to design a single component vector seems worthwhile and should be further explored.

\section{Appendix A. Supplementary data}

Supplementary data associated with this article can be found, in the online version, at doi:10.1016/j.jconrel.2009.12.025.

\section{References}

[1] F. Heitz, M.C. Morris, G. Divita, Twenty years of cell-penetrating peptides: from molecular mechanisms to therapeutics, British Journal of Pharmacology 157 (2009) 195-206.

[2] H. Brooks, B. Lebleu, E. Vives, Tat peptide-mediated cellular delivery: back to basics, Advanced Drug Delivery Reviews 57 (2005) 559-577.

[3] S. Trabulo, M. Mano, H. Faneca, A.L. Cardoso, S. Duarte, A. Henriques, et al., S4(13)PV cell penetrating peptide and cationic liposomes act synergistically to mediate intracellular delivery of plasmid DNA, Journal of Gene Medicine 10 (2008) 1210-1222

[4] L.A. Kunz-Schughart, Multicellular tumor spheroids: intermediates between monolayer culture and in vivo tumor, Cell Biology International 23 (1999) 157-161.

[5] C.D. Davies, D.A. Berk, A. Pluen, R.K. Jain, Comparison of $\operatorname{IgG}$ diffusion and extracellular matrix composition in rhabdomyosarcomas grown in mice versus in vitro as spheroids reveals the role of host stromal cells, British Journal of Cancer 86 (2002) 1639-1644.

[6] A.F.A. Saleh, H.S. Aojula, A. Pluen, Enhancement of gene transfer using YIGSR analog of Tat-derived peptide, Biopolymers 89 (2008) 62-71.

[7] H.A. Perry, A.F.A. Saleh, H. Aojula, A. Pluen, YOYO as a dye to track penetration of LK15 DNA complexes in spheroids: use and limits, Journal of Fluorescence 18 (2008) 155-161.

[8] J. Dufourcq, W. Neri, N. Henry-Toulme, Molecular assembling of DNA with amphipathic peptides, FEBS Letters 421 (1998) 7-11.

[9] J.C.M. Stewart, Colorimetric determination of phospholipids with ammonium ferrothiocyanate, Analytical Biochemistry 104 (1980) 10-14.

[10] K. Rittner, A. Benavente, A. Bompard-Sorlet, F. Heitz, G. Divita, R. Brasseur, et al., New basic membrane-destabilizing peptides for plasmid-based gene delivery in vitro and in vivo, Molecular Therapy 5 (2002) 104-114. 
[11] J. Hed, G. Hallden, S.G. Johansson, P. Larsson, The use of fluorescence quenching in flow cytofluorometry to measure the attachment and ingestion phases in phagocytosis in peripheral blood without prior cell separation, Journal of Immunological Methods 101 (1987) 119-125.

[12] T. Mosmann, Rapid colorimetric assay for cellular growth and survival application to proliferation and cyto-toxicity assays, Journal of Immunological Methods 65 (1983) 55-63.

[13] C. Ramaswamy, T. Sakthivel, A.F. Wilderspin, A.T. Florence, Dendriplexes and their characterisation, International Journal of Pharmaceutics 254 (2003) 17-21.

[14] P.L. Felgner, T.R. Gadek, M. Holm, R. Roman, H.W. Chan, M. Wenz, et al., Lipofection: a highly efficient, lipid-mediated DNA-transfection procedure, Proceedings of the National Academy of Science of the USA 84 (1987) 7413-7417.

[15] Y. Murayama, M. Sano, Exchange of counterions in DNA condensation, Biopolymers 77 (2005) 354-360.

[16] W.T. Godbey, K.K. Wu, A.G. Mikos, Size matters: molecular weight affects the efficiency of poly(ethylenimine) as a gene delivery vehicle, Journal of Biomedical Materials Research 45 (1999) 268-275.

[17] J.Y. Shin, D. Suh, J.M. Kim, H.G. Choi, J.A. Kim, J.J. Ko, et al., Low molecular weight polyethylenimine for efficient transfection of human hematopoietic and umbilical cord blood-derived CD34+ cells, Biochimica et Biophysica Acta 1725 (2005) 377-384.

[18] J.P. Richard, K. Melikov, E. Vives, C. Ramos, B. Verbeure, M.J. Gait, et al., Cellpenetrating peptides. A reevaluation of the mechanism of cellular uptake, Journal of Biological Chemistry 278 (2003) 585-590.

[19] P. Sampath, T.D. Pollard, Effects of cytochalasin, phalloidin, and $\mathrm{Ph}$ on the elongation of actin-filaments, Biochemistry 30 (1991) 1973-1980.

[20] J.E. Schnitzer, P. Oh, E. Pinney, J. Allard, Filipin-sensitive caveolae-mediated transport in endothelium - reduced transcytosis, scavenger endocytosis, and capillary-permeability of select macromolecules, Journal of Cell Biology 127 (1994) 1217-1232.

[21] L.H. Wang, K.G. Rothberg, R.G.W. Anderson, Mis-assembly of clathrin lattices on endosomes reveals a regulatory switch for coated pit formation, Journal of Cell Biology 123 (1993) 1107-1117.

[22] P. Watson, A.T. Jones, D.J. Stephens, Intracellular trafficking pathways and drug delivery: fluorescence imaging of living and fixed cells, Advanced Drug Delivery Reviews 57 (2005) 43-61.

[23] M.L. Forrest, D.W. Pack, On the kinetics of polyplex endocytic trafficking: implications for gene delivery vector design, Molecular Therapy 6 (2002) $57-66$.
[24] K. Rittner, A. Benavente, A. Bompard-Sorlet, F. Heitz, G. Divita, R. Brasseur, et al, New basic membrane-destabilizing peptides for plasmid-based gene delivery in vitro and in vivo, Molecular Therapy 5 (2002) 104-114.

[25] K. Dardousis, C. Voolstra, M. Roengvoraphoj, A. Sekandarzad, S. Mesghenna, ]. Winkler, et al., Identification of differentially expressed genes involved in the formation of multicellular tumor spheroids by HT-29 colon carcinoma cells, Molecular Therapy 15 (2007) 94-102.

[26] J. Dufourcq, W. Neri, N. Henry-Toulme, Molecular assembling of DNA with amphipathic peptides, FEBS Letters 421 (1998) 7-11.

[27] D. Soundara Manickam, H.S. Bisht, L. Wan, G. Mao, D. Oupicky, Influence of TATpeptide polymerization on properties and transfection activity of TAT/DNA polyplexes, Journal of Controlled Release 102 (2005) 293-306.

[28] S. Yang, D.J. Coles, A. Esposito, D.J. Mitchell, I. Toth, R.F. Minchin, Cellular uptake of self-assembled cationic peptide-DNA complexes: multifunctional role of the enhancer chloroquine, Journal of Controlled Release 135 (2009) 159-165.

[29] R.M. Sutherland, Cell and environment interactions in tumor microregions: the multicell spheroid model, Science 240 (1988) 177-184.

[30] H.R. Mellor, L.A. Davies, H. Caspar, C.R. Pringle, S.C. Hyde, D.R. Gill, et al. Optimising non-viral gene delivery in a tumour spheroid model, Journal of Gene Medicine 8 (2006) 1160-1170.

[31] K. Kostarelos, D. Emfietzoglou, A. Papakostas, W.H. Yang, A.M. Ballangrud, G. Sgouros, Engineering lipid vesicles of enhanced intratumoral transport capaabilities: correlating liposome characteristics with penetration into human prostate tumor spheroids, Journal of Liposome Research 15 (2005) 15-27.

[32] M. Wartenberg, H. Acker, Quantitative recording of vitality patterns in living multicellular spheroids by confocal microscopy, Micron 26 (1995) 395-404.

[33] A. Pluen, Y. Boucher, S. Ramanujan, T.D. McKee, T. Gohongi, E. di Tomaso, et al., Role of tumor-host interactions in interstitial diffusion of macromolecules: cranial vs. subcutaneous tumors, Proceedings of the National Academy of Sciences USA 98 (2001) 4628-4633.

[34] P. Lundberg, S. El-Andaloussi, T. Sutlu, H. Johansson, U. Langel, Delivery of short interfering RNA using endosomolytic cell-penetrating peptides, Faseb Journal 21 (2007) 2664-2671.

[35] P. Midoux, A. Kichler, V. Boutin, J.C. Maurizot, M. Monsigny, Membrane permeabilization and efficient gene transfer by a peptide containing several histidines, Bioconjugate Chemistry 9 (1998) 260-267.

[36] S.L. Lo, S. Wang, An endosomolytic Tat peptide produced by incorporation of histidine and cysteine residues as a nonviral vector for DNA transfection, Biomaterials 29 (2008) 2408-2414. 